\title{
Microstructural Study on Oxygen Permeated Arc Beads
}

\author{
Kuan-Heng Liu, Yung-Hui Shih, Guo-Ju Chen, and Jaw-Min Chou \\ Department of Materials Science and Engineering, I-Shou University, Kaohsiung 840, Taiwan \\ Correspondence should be addressed to Guo-Ju Chen; gjchen@isu.edu.tw and Jaw-Min Chou; jmchou@isu.edu.tw
}

Received 30 September 2014; Accepted 1 January 2015

Academic Editor: Miguel A. Garcia

Copyright (C) 2015 Kuan-Heng Liu et al. This is an open access article distributed under the Creative Commons Attribution License, which permits unrestricted use, distribution, and reproduction in any medium, provided the original work is properly cited.

\begin{abstract}
We simulated short circuit of loaded copper wire at ambient atmosphere and successfully identified various phases of the arc bead. A cuprous oxide flake was formed on the surface of the arc bead in the rapid solidification process, and there were two microstructural constituents, namely, $\mathrm{Cu}-\kappa$ eutectic structure and solutal dendrites. Due to the arc bead formed at atmosphere during the local equilibrium solidification process, the phase of arc bead has segregated to the cuprous oxide flake, $\mathrm{Cu}-\kappa$ eutectic, and $\mathrm{Cu}$ phase solutal dendrites, which are the fingerprints of the arc bead permeated by oxygen.
\end{abstract}

\section{Introduction}

At present, the critical evidences for electrical fire cases determined by fire investigator around the world are not convincing. The trace evidences of electrical molten marks found at the fire scene may provide the solution. Short circuit can cause fire, while fire can also lead to short circuit. The "electric melted mark" can be divided into two kinds further, namely, the "fire-causing arc bead" and "fire-resulting arc bead." Since electrical molten marks are common at the fire scene, the puzzling question remains that whether the electrical molten marks are the actual cause of fire or are caused by wiring short circuit as the insulating cover of wire is destroyed by combustion flame. Up till now, fire investigators are still unable to identify the above two kinds of arc beads [1].

In Japan, the electrical molten marks that cause fire are called "fire-causing arc bead" or "Primary Molten Mark (PMM)" while those resulting from fire are called "fireresulting arc bead" or "Secondary Molten Mark (SMM)." At present, many fire investigators still compare the size of short-circuit arc beads, as well as the external brightness and color of the molten marks, by visual inspection according to the identification method stated in the "Electrical Fire Cause and Identification" published by Tokyo Fire Department, Investigation Section, 1971, so as to analyze whether the electrical molten marks are the fire-causing arc bead [2]. The macroscopic comparison method of visual observation is prone to human subjective bias. As a result, the identification of electrical molten marks has been disputed for a long time without any final conclusions [3-5]. To identify the fire cause by arc bead from electrical molten marks in fire scene is a challenge for the fire investigators. Such uncertainty in fire identification has undermined the public reliance of the investigation results of fire causes and has a strong impact on the credibility of evidences in judicial judgment of fire cases.

Anderson [6] analyzed the composition profile on the surface of electrical molten marks by Auger electron spectroscopy. The results found that the molten marks of electrical wire short circuit would adsorb ambient gases, thus reflecting the ambient atmosphere conditions of electrical wire short circuit. The compositions on surface of electrical molten marks include oxygen. Howitt [7] suggested that the solubility of oxygen in liquid copper would decline greatly from the viewpoints of thermodynamics and kinetics. Lee et al. [8] used Raman spectroscopy to identify the carbonized residue of electrical molten marks; there was graphitized carbon in the fire-causing arc beads. Chen et al. [9] used the secondary ion mass spectrometer to measure the depth profile; the surface layer enriched with $\mathrm{C}, \mathrm{Cl}$, and $\mathrm{O}$ was observed in the fire-causing arc beads.

This study aimed to explore the microstructural revolution of the arc beads while the electrical copper wire is short-circuited at ambient atmosphere and discuss the solidification of liquid copper at atmosphere, so as to make scientific definition and more precise description of the phase identification of the fire-causing arc bead [10]. 


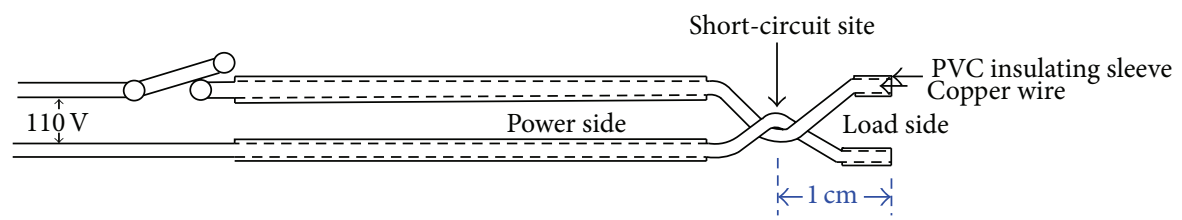

FIgURE 1: Schematic diagram of the short-circuit experiment.

\section{Materials and Methods}

The experimental materials for short circuit were two electrical copper wires (99.99\% purity) in a length of $10 \mathrm{~cm}$ and a diameter of $1.2 \mathrm{~mm}$, sleeved with PVC. The short circuit of the electric wire for the "fire-causing arc bead" was conducted at ambient atmosphere. The blowout and the solidification of wire are completed instantaneously as the short circuit of loaded wire even without ignition of fire. Therefore, in this experiment, the short site was preset $1 \mathrm{~cm}$ away from the end (load side). The insulation PVC layer of the preset short site was peeled off and two wires were twisted to make contact. The contact copper wires were placed at ambient atmosphere, and the other end (power side) was connected to the 110 Volt and $60 \mathrm{~Hz}$ AC power supply as shown in Figure 1. As the power supply turned on, the two copper wires formed short circuit instantly until the short-circuit current blew out the conductors. The arc bead samples were obtained in the blown part of wire.

The load side short-circuit arc bead samples were taken out and soaked in acetone and clean arc bead samples surface by the ultrasonic oscillator. The clean arc bead samples were then placed in the moisture proof box at room temperature for natural drying. The morphology and the composition of the dried samples were observed by the FE-SEM (HITACHI S-4700 Field Emission-SEM), and then the microarea X-ray diffraction analysis on the samples was conducted by the XRD diffractometer (PANalytical X'PERT PRO XRD). The microstructure on the samples was observed by FIB-SEM (SEIKO SMI3050SE Dual-Beam FIB-SEM Hybrid System) and the sampling site was bombardment cut by gallium ion beam to prepare the TEM specimens. The chemical composition of the specimens was analyzed by SEM attached EDS (METEK, $5 \leqq Z \leqq 92$ ).

Then, the electronic diffraction patterns, bright field and dark field images of the specimens, were conducted by the TEM (FEI Tecnai $G^{2} 20$ S-Twin). The distances $(R)$ between diffraction spot and transmitted electron beam in the diffraction pattern of specimens were measured to find out their crystallographic relationship. As the reciprocal of reciprocal lattice vector length is the interplanar spacing (d) of crystal $(h k l)$ plane, calculate the interplanar spacing corresponding to the diffraction point according to $R$ value; and then the interplanar spacings are derived from $R d=$ const. [11]. Various corresponding indices of plane $(h k l)$ are obtained; the structure and phase identification of the constituents of specimens are analyzed after comparing with JCPD cards.

\section{Results and Discussion}

After 120 times of short-circuit experiments, the measurements on the short-circuit current showed that the triggered short-circuit current reached as high as 750 ampere during short circuiting. The part of wire at the power side, where the short-circuit current passed through, exhibited a hightemperature red hot status. Short-circuit current causes high temperature to decompose PVC insulator of the power side wires. The PVC pyrolysis produced flammable gases. The short-circuit arc not only ignited pyrolysis gases to bring about burning insulator but also resulted in the open circuit of copper conductor. This part of melted copper was heated and liquefied instantly. When the heating rate of the melted liquid copper was much greater than the cooling rate and the overheating was formed in short-circuit contact, the liquid copper was spattered by arc. Thus, the two shortcircuited wires were melted to break in contact instantly. The splashing liquid copper droplets were condensed to fine beads immediately in the atmosphere due to surface tension. Moreover, the residual liquid copper adhering to the four molten ends of the two short-circuited wires was solidified into the arc bead instantaneously.

By using FIB-SEM to observe the microstructure constituents of those load side arc bead samples, which exhibit the faceted morphology layer on the surface of the samples, the faceted layer is about $6 \mu \mathrm{m}$ thick (Figures 2(a) and 2(b)). The microstructure under the faceted layer is a mixture consisting of two microstructure constituents, namely, polyphase eutectic structure (Figure 3(a)) and dendrite with surface precipitate (Figure 4(a)). The polyphase eutectic structure is characterized by two phases, which are rod-shaped phase and a matrix of continuous phase.

Gallium ion beam was used for bombardment cutting on the surface layer of the above arc bead samples for TEM sampling (Figure 2(b)). According to EDS analysis, the surface layer specimen of arc bead is composed of copper and oxygen elements (Figure 2(c)). TEM electron diffraction analysis was also conducted on the specimen (Figure 2(f)). By checking JCPD cards corresponding interplanar spacing, it was found that the faceted layer on the surface of the arc bead samples is the cuprous oxide of lattice constant $0.4269 \mathrm{~nm}$ with simple cubic structure.

In Figure 3(a), the polyphase eutectic structure under the cuprous oxide layer of the arc bead samples was observed by FIB-SEM. From TEM electron diffraction results, Figures $3(\mathrm{c}), 3(\mathrm{~d})$, and 3(e), the eutectic matrix is the $\mathrm{Cu}$ phase with a face-centered cubic structure and a lattice constant 
TABLE 1: Calculation interplanar spacing distances of the dendritic surface precipitate from electron beam diffraction pattern and comparison with $\mathrm{Cu}_{2} \mathrm{O}$ standard data (JCPD 05-0667).

\begin{tabular}{|c|c|c|c|c|c|}
\hline Spot & $\begin{array}{c}\text { Measured } \\
\text { reciprocal } \\
\text { position }(1 / \mathrm{nm})\end{array}$ & Degrees to spot 1 & $\begin{array}{c}\text { Calculated interplanar } \\
\text { distance }(\AA)\end{array}$ & $\begin{array}{c}\text { Standard interplanar } \\
\text { distance }(\AA)\end{array}$ & $\begin{array}{c}\mathrm{Cu}_{2} \mathrm{O} \text { crystalline plane } \\
(h k l)\end{array}$ \\
\hline 1. & 3.317 & - & 3.0147 & 3.0200 & $(110)$ \\
\hline 2. & 4.085 & $34.73^{\circ}$ & 2.4478 & 2.4650 & (111) \\
\hline 3. & 2.318 & $90.00^{\circ}$ & 4.3151 & 4.2690 & $(001)$ \\
\hline 4. & 4.075 & $145.31^{\circ}$ & 2.4537 & 2.4650 & $(\overline{111})$ \\
\hline
\end{tabular}

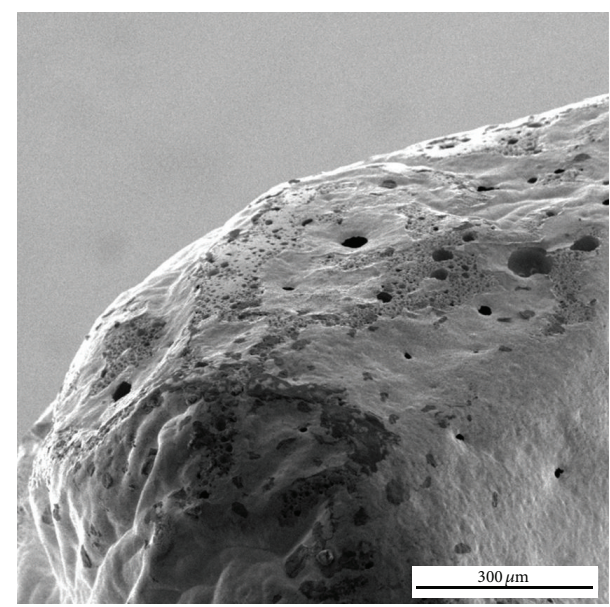

(a)

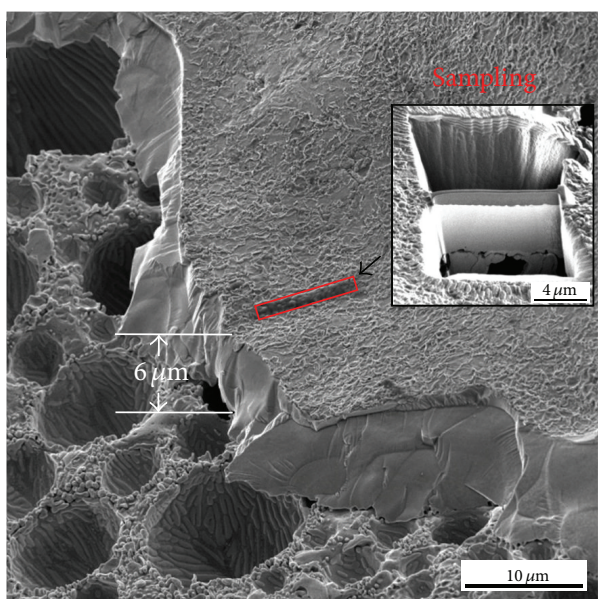

(b)

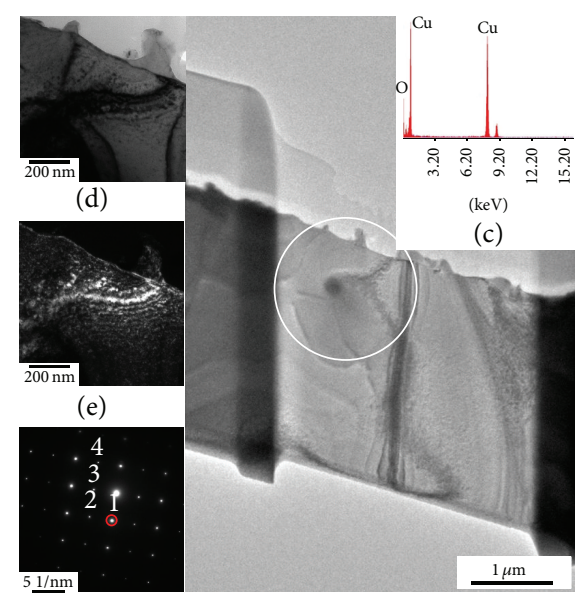

(f)

Figure 2: Microscopic photos of the surface layer. (a) Faceted surface layer observed through FIB-SEM, (b) sampling region of TEM specimen on the faceted surface layer, (c) EDS spectrum, (d) TEM bright field image, (e) dark field image, and (f) corresponding diffraction pattern along $[1 \overline{1} \overline{2}]$ direction.

of $0.3613 \mathrm{~nm}$, and the rod-shaped phase is the cuprous oxide with a simple cubic structure, at a lattice constant of $0.4269 \mathrm{~nm}$. The corresponding EDS spectrum, Figures 3(b) and 3(f), also confirmed the chemical composition of the eutectic matrix and the rod-shaped phase, respectively.

In Figure 4, the dendrite, tipped with precipitate, is the microstructure of another constituent under the oxide layer of the arc bead. These dendrites exhibit the nonfaceted growth morphology and outward growth derived from the unfused wire end and immersed in eutectic [12]. The chemical compositions of dendritic second arm and precipitate in the specimen are copper element (Figure 4(c)) and include copper-oxygen elements, respectively (Figure $4(\mathrm{~g})$ ). The structure analysis of the dendritic second arm (Figures 4(d), 4(e), and 4(f)) and tipped precipitate (Figures 4(h), 4(i), and $4(\mathrm{j})$ ) shows that the dendrite is the $\mathrm{Cu}$ phase with a facecentered cubic structure, at a lattice constant of $a=0.3615 \mathrm{~nm}$, and the precipitate on the dendritic surface is the cuprous oxide with a simple cubic structure, at a lattice constant of $0.4269 \mathrm{~nm}$ (Figures 4(g) and 4(j) and Table 1). 


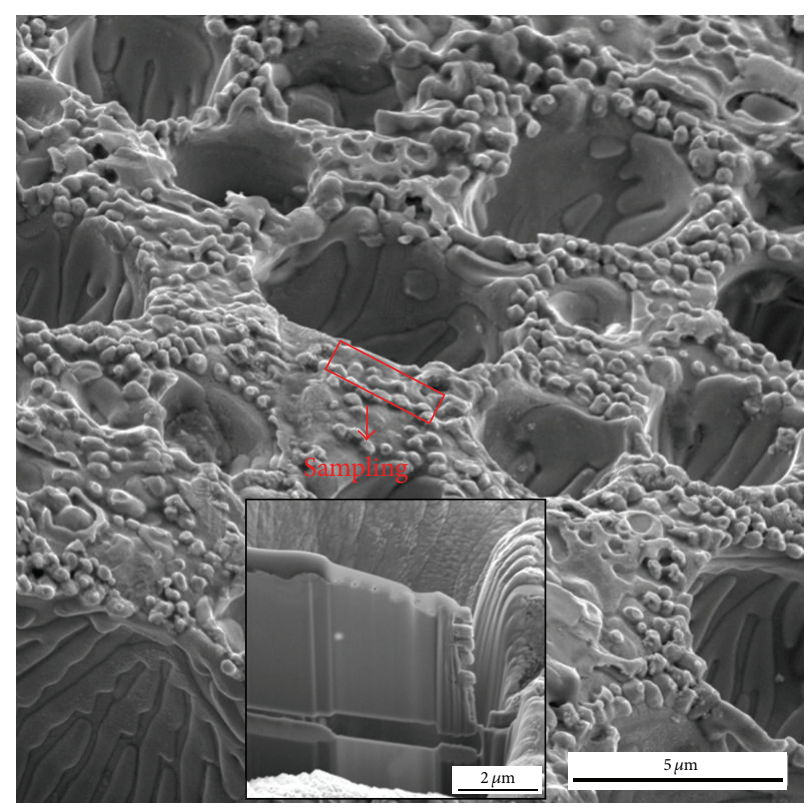

(a)

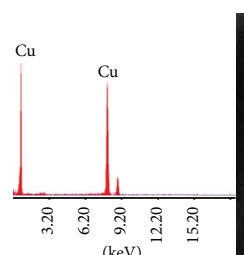

(b)

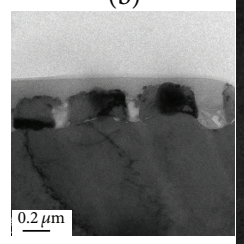

(c)

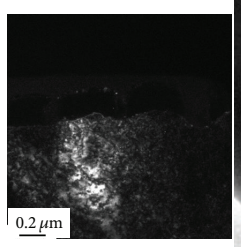

(d)

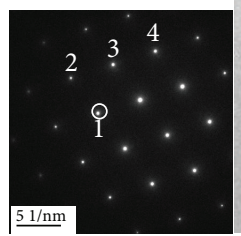

(e)

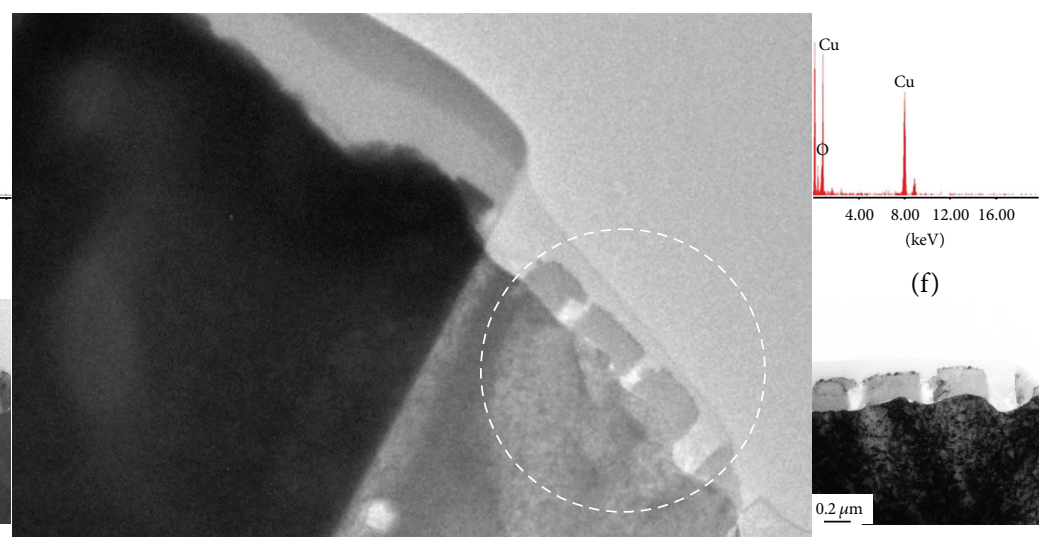

(g)

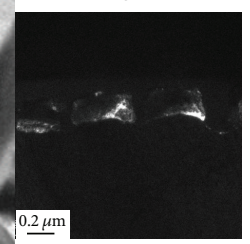

(h)

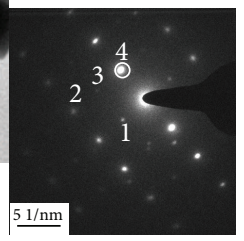

(i)

FIGURE 3: TEM analysis of the eutectic phase. (a) Microstructure of the eutectic phase and the sampling of TEM specimen, (b) EDS spectrum of the matrix, (c) TEM bright field of the matrix, (d) dark field of the matrix, (e) corresponding diffraction pattern of the matrix along [1 $\overline{1} 0$ ] direction, (f) EDS spectrum of the rod-shaped phase, (g) TEM bright field of the rod-shaped phase, (h) dark field of the rod-shaped phase, and (i) corresponding diffraction pattern of the rod-shaped phase along [1 $\overline{1} \overline{2}]$ direction. 


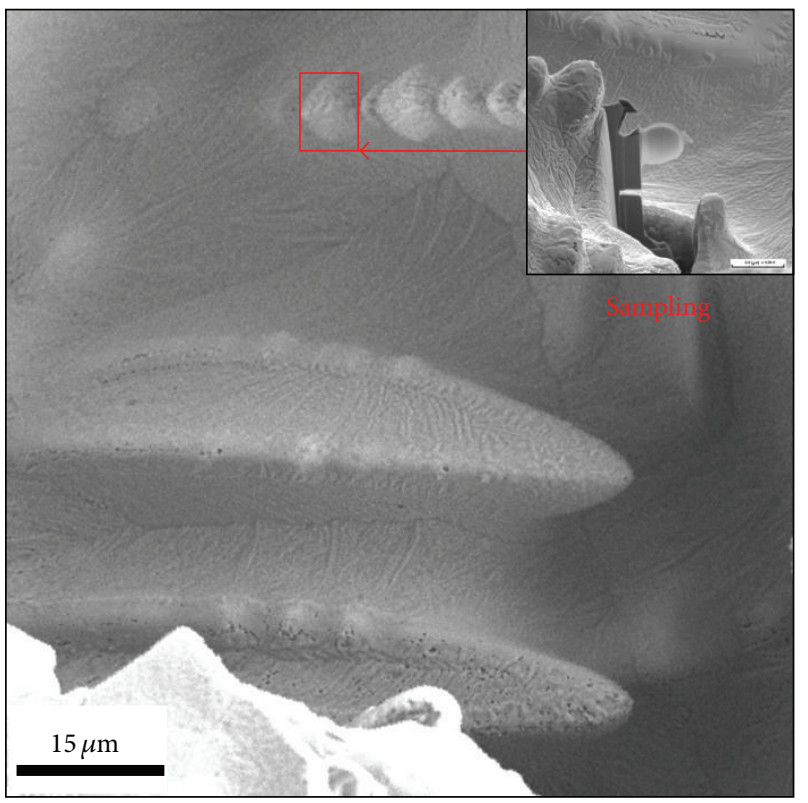

(a)

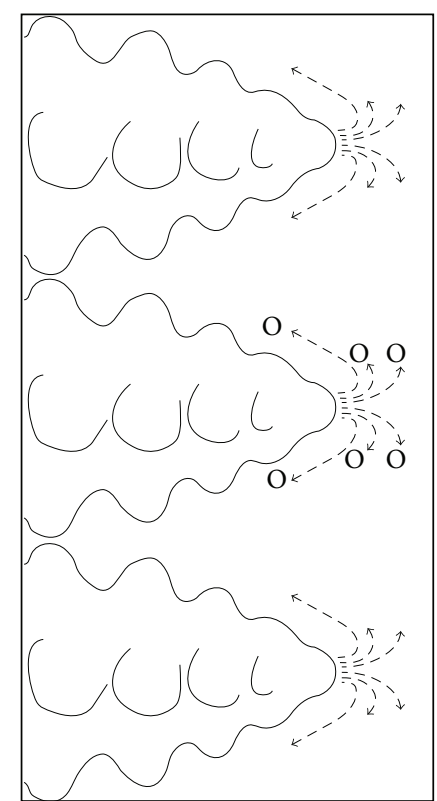

(b)

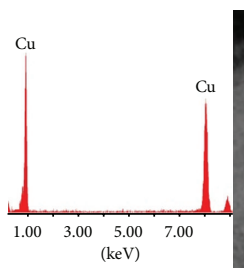

(c)

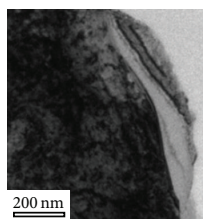

(d)

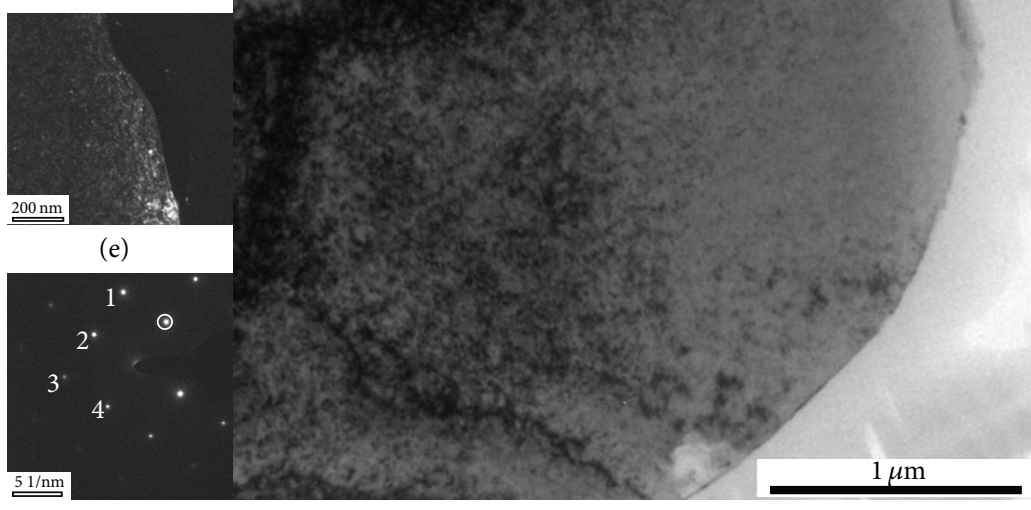

(f)

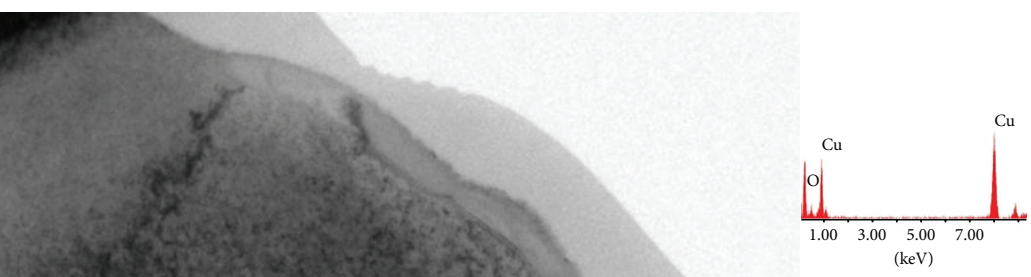

(g)

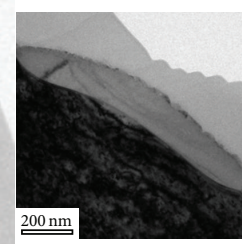

(h)

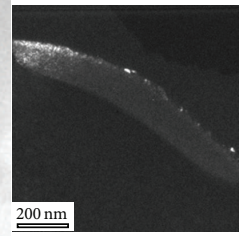

(i)

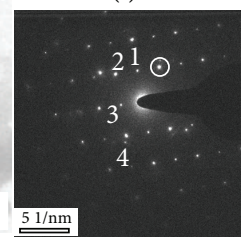

(j)

FIgUre 4: Analysis of the dendrite tipped with precipitate. (a) Microstructure of the dendrite tipped with precipitate observed by FIB-SEM and the sampling of TEM specimen, (b) schematic diagram of dendritic growth, (c) EDS spectrum of the dendrite, (d) TEM bright field of the dendrite, (e) dark field of the dendrite, (f) corresponding diffraction pattern of the matrix along [001] direction, (g) EDS spectrum of the precipitate phase, (h) TEM bright field of the precipitate phase, (i) dark field of the precipitate phase, and (j) corresponding diffraction pattern of the $\mathrm{Cu}_{2} \mathrm{O}$ phase along [110] direction. 


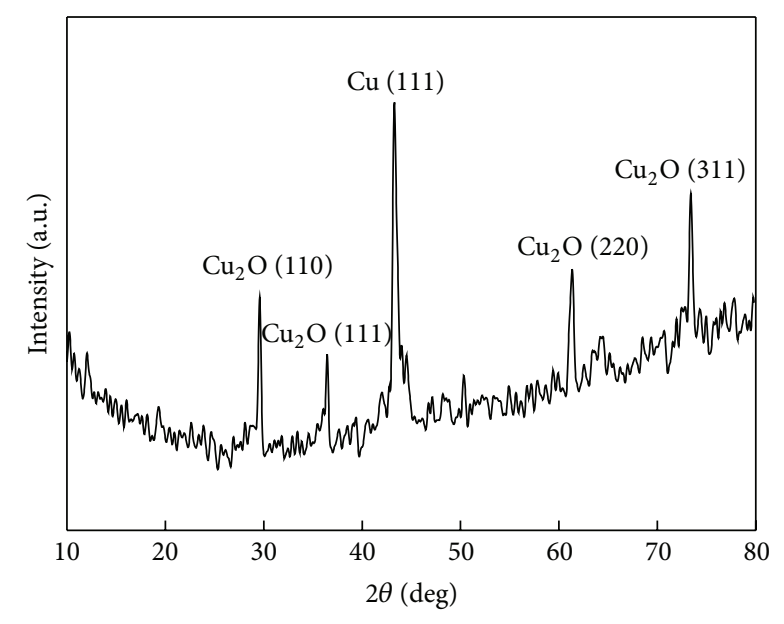

FIGURE 5: XRD microanalysis of the faceted surface of arc bead.

The unmelted part of conductor is the heat extraction source. When the molten mark solution temperature is lower than $1358 \mathrm{k}$, the copper atoms in liquid will be heterogeneously nucleated as crystal embryos on the interface at the solid end of conducting wire that is not yet melted and then grow towards $\langle 100\rangle$ direction to form columnar crystals. When the columnar crystals grow, the oxygen atoms are rejected continuously into the liquid and the solute concentration of solution between columnar crystals is therefore enhanced (Figure 4(b)). Thus the solution forms constitutional undercooling between columnar crystals. The secondary arms grow along $\langle 100\rangle$ direction perpendicular to primary crystals. This kind of dendrite also is known as solutal dendrite.

According to the diffraction pattern of XRD on the faceted surface of the samples (Figure 5), the peaks at $2 \theta=$ $29.549^{\circ}, 36.413^{\circ}, 61.349^{\circ}$, and $73.534^{\circ}$ are $\mathrm{Cu}_{2} \mathrm{O}$ (110), (111), (220), and (311), and the peak at $2 \theta=43.552^{\circ}$ is $\mathrm{Cu}$ (111).

The experimental results showed that due to high current density overheating, the liquid copper at the melting site of the short-circuited wire adsorbs oxygen from air. According to the above identification results, the surface layer of the fire-causing arc bead is the faceted cuprous oxide. The microstructure under the faceted cuprous oxide layer is a mixture consisting of two constituents, which are copper-cuprite eutectic structure and solutal $\mathrm{Cu}$ dendrites; the schematic diagram is shown as Figure 6.

When wiring short circuit occurred at atmosphere, the dissolved oxygen in liquid copper on the molten end of the electrical copper wire follows Sievert's law. The solubility of the dissolved diatomic gases in melting is proportional to the square root of partial pressure of oxygen, $C_{g}=K\left(p_{o}\right)^{1 / 2}$, and it is also the temperature function, $C_{g}=\operatorname{Bexp}(-Q / R T)[13]$. According to $\mathrm{Cu}-\mathrm{O}$ phase diagram [14], the oxygen solubility enhances in the liquid copper at high temperature as the rapid heating of the wire by short-circuit current.

From the gas/liquid interface (the surface of fire-causing arc bead), the oxygen dissolved in the liquid copper of the arc bead to form $\mathrm{Cu}-\mathrm{O}$ solution, the liquid copper is the solvent, and the dissolved oxygen atom is the solute. The oxygen concentration of the molten arc bead profile forms diffusion distributed curve and decreases with an increasing diffusion distance from the surface of arc bead. Therefore, the oxygen concentration is the highest on surface of the melting the arc bead at ambient atmosphere.

In $\mathrm{Cu}-\mathrm{O}$ solution, copper dendrites grow up; oxygen solute is being repelled from the $\mathrm{Cu}$-dendrites tip constantly and forms cuprous oxide on dendritic surface (Figures 4(a) and $4(\mathrm{~b})$ ). These dendrites are solutal dendrites. Since the growth of the high-index planes with higher surface energy is quicker than low-index planes in the solidified $\mathrm{Cu}$ phase solutal dendrites, thus leaving the low-index $\{111\}$ plane of copper in the final solidification $[15,16]$, XRD results exhibited strong $\mathrm{Cu}$ (111) texture in the arc bead.

According to the $\mathrm{Cu}-\mathrm{O}$ phase diagram [17], as shown in Figure 7, when $\log P_{\mathrm{O}_{2}}=-0.7$, the three-phase equilibrium point of $\mathrm{Cu}-\mathrm{O}$ system lies nearby the hypoeutectic composition between $\kappa$-phase and $\tau$-phase. In this experiment, the surface of the arc bead is the cuprous oxide ( $\kappa$-phase) coating layer, and the constituents of the arc bead include $\mathrm{Cu}-\kappa$ eutectic structure and solutal $\mathrm{Cu}$-dendrites; meanwhile, the eutectic structure consists of rod-shaped $\kappa$-phase and $\mathrm{Cu}$ phase matrix. During the solidification of the rapid cooling process, the liquid solution forms two liquids miscibility gap, $L \rightarrow L_{1}+L_{2}$, below $T=1618 \mathrm{~K}$ (critical point). When the surface temperature is decreased below $T=1502 \mathrm{~K}$ (freezing point of cuprous oxide), $L_{2} \rightarrow \kappa, L_{2}$ is solidified into cuprous oxide layer, which prevents the oxygen at ambient atmosphere from further dissolving into the molten arc bead continuously. When the molten arc bead solution is cooled below $T=1496 \mathrm{~K}$ (monotectic point), $L_{1}+L_{2} \rightarrow L_{1}+\kappa$ [18], the cuprous oxide layer becomes thick by the monotectic transformation. The oxygen content of arc bead is 0.33 ( $\mathrm{Xo}=$ 0.33 ), and, therefore, the molar fraction of oxygen inside the arc bead is less than $0.33(\mathrm{Xo}<0.33)$.

When the melted solution inside the arc bead is further cooled below $T=1358 \mathrm{~K}$ (melting point of copper), copper atoms in liquid heterogeneously nucleate at the melted/unmelted interface of wire [19]. The solid end of wire becomes the heat conductor (the heat sink). The copper atoms on the liquid side crystallize at the interface by the capillarity and thermal conduction. The kinetics of transfer of atoms from the liquid to the crystal is rapid so that it can be neglected; thus, the solidified $\mathrm{Cu}$ phase dendrites appear to be nonfaceted crystal. The growth direction of cellular dendrites is opposite to the direction of heat flow [20]. The solutal $\mathrm{Cu}$-dendrites grow rapidly towards the molten arc bead surface layer from the unmelted solid end section of wire. The solutal $\mathrm{Cu}$-dendrites form so that solute is repelled into the liquid and enhances the solution concentration. As this sequence of events continues, the oxygen content becomes progressively richer in solution, which may even reach the eutectic composition of the $\mathrm{Cu}-\kappa$ phase based on Scheil's equation $C_{l}=C_{0}\left(1-f_{s}\right)^{(k-1)},\left(C_{l}\right.$ : liquid concentration, $C_{0}$ : initial concentration, $f_{s}$ : volume fraction of solid, and $k$ : equilibrium distribution coefficient) [21]. At this stage of solidification, the constitutional effect of liquid/solid interface rejecting solute forms constitutional supercooling, which is the driving force for the continuous 


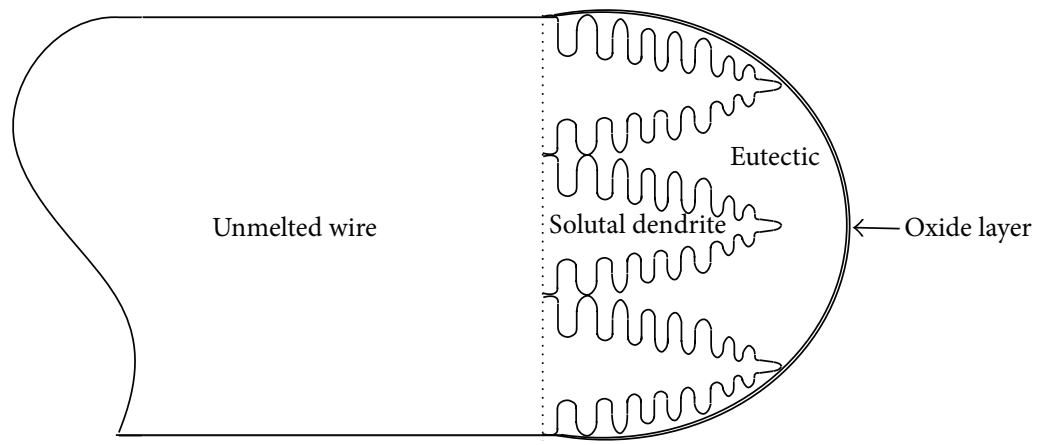

FIGURE 6: Schematic microstructure of arc bead permeated by oxygen.

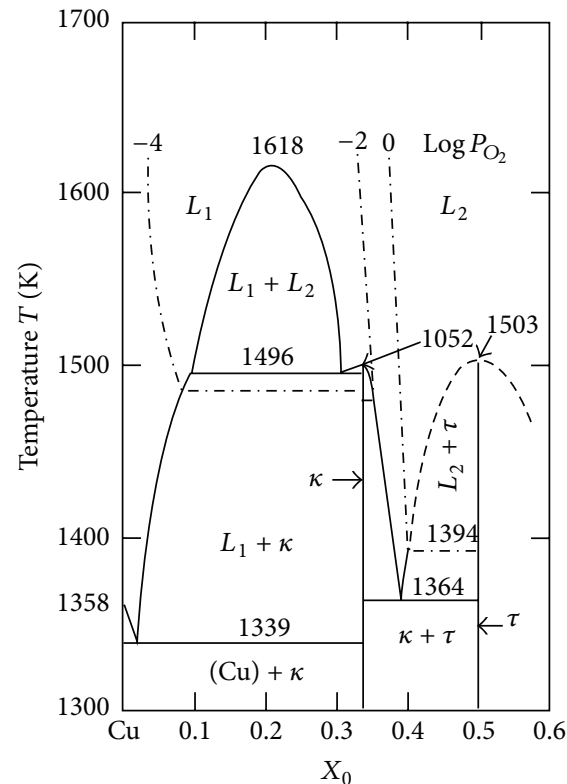

Figure 7: In $\mathrm{Cu}-\mathrm{O}$ phase diagram, $\mathrm{Cu}-\kappa$ eutectic point $\mathrm{Xo}=0.017$ (at $T=1339 \mathrm{~K}$ ) [17].

growth of solutal dendrites [13]. The solutal dendrites grow along the preferred crystallographic direction $\langle 001\rangle$ and opposite to the direction of the heat flow, so solutal $\mathrm{Cu}-$ dendrites can be observed under the cuprous oxide layer of arc bead surface. The residual solution pushed by solutal $\mathrm{Cu}-$ dendrites growth to the inferior of cuprous oxide layer of the arc bead surface forms the eutectic composition solution. When the temperature drops below $T=1339 \mathrm{~K}$ (eutectic point), $L_{1} \rightarrow(\mathrm{Cu})+\kappa$, the residual eutectic composed solution is solidified into $\mathrm{Cu}-\kappa$ eutectic structure. Therefore, the eutectic structure under the cuprous oxide surface layer of molten arc bead is the final transient in solidification of the fire-causing arc bead.

\section{Conclusion}

According to the experimental results, at ambient atmosphere, the liquid copper of molten arc bead may adsorb ambient oxygen, and a cuprous oxide coating is formed on the arc bead surface layer. The hypoeutectic composition solution inside molten arc bead solidifies into solutal $\mathrm{Cu}$-dendrites and $\mathrm{Cu}-\kappa$ eutectic. The growth of $\mathrm{Cu}$-dendrites inside the molten arc bead starts at the unmelted solid end section of wire and ends somewhere nearby the cuprous oxide coating of the arc bead surface. Thus, $\mathrm{Cu}-\kappa$ eutectic structure and solutal $\mathrm{Cu}$-dendrites microstructure can be observed under the cuprous oxide coating. According to XRD results, the solidification of the $\mathrm{Cu}$-dendrites and the growth of highindex planes with higher surface energy are quicker than lowindex planes, thus leaving the low-index $\{111\}$ plane in the final solidification of $\mathrm{Cu}$-dendrites.

Therefore, the cuprous oxide surface layer and the microstructure constituents of solutal $\mathrm{Cu}$-dendrites and $\mathrm{Cu}$ $\kappa$ eutectic structure are the characteristic feature, as well as the fingerprint of the fire-causing arc bead permeated by oxygen, for the short circuit of electrical copper wire occurs at an ambient atmosphere before fire. Instead of visual inspection or empirical rule, the microstructure of electrical molten mark can be analyzed precisely by using FIB-SEM and TEM. As a result, convincing scientific trace evidences can be provided in court.

\section{Conflict of Interests}

The authors declare that there is no conflict of interests regarding the publication of this paper.

\section{Acknowledgments}

The authors are grateful to the Micro- and Nano-Analysis Laborotary and Physical Measurement Laborotary at I-Shou University and Fire Bureau of Kaohsiung City, and the Grant under ISU103-02-06, ISU101-02-10, NSC101-2221-E-214-024, and MOST103-2221-E-214-006.

\section{References}

[1] Fire Investigation Divison, White Paper on Fire Service, National Fire Agency, Ministry of the Interior Taiwan R.O.C, Taipei, Taiwan, 2009. 
[2] Fire Investigation Section of Tokyo Fire Department, "Electrical Fire Cause and Identification," p. 17, 1971.

[3] E. P. Lee, H. Ohtani, T. Seki, H. Hasegawa, S. Imada, and I. Yashiro, "A fundamental study on electrical molten marks," Bulletin of Japan Association for Fire Science and Engineering, vol. 51, no. 1, pp. 1-12, 2001.

[4] Q. Y. Chen and S. L. Zhu, "The surface analysis of copper arc beads-a critical review," Fire Safety Journal, pp. 42-46, 1998.

[5] V. Babrauskas, "Arc beads from fires: can "cause" beads be distinguished from "victim" beads by physical or chemical testing?" Journal of Fire Protection Engineering, vol. 14, no. 2, pp. 125-147, 2004.

[6] R. N. Anderson, "Surface analysis of electrical arc residues in fire investigation," Journal of Forensic Sciences, vol. 34, no. 3, pp. 633-637, 1989.

[7] D. G. Howitt, "The surface analysis of copper arc beads-a critical review," Journal of Forensic Sciences, vol. 42, no. 4, pp. 608-609, 1997.

[8] E.-P. Lee, H. Ohtani, Y. Matsubara et al., "Study on discrimination between primary and secondary molten marks using carbonized residue," Fire Safety Journal, vol. 37, no. 4, pp. 353$368,2002$.

[9] C. Y. Chen, Y. C. Ling, J. T. Wang, and H. Y. Chen, "SIMS depth profiling analysis of electrical arc residues in fire investigation," Applied Surface Science, vol. 203-204, pp. 779-784, 2003.

[10] P. M. L. Sandercock, "Fire investigation and ignitable liquid residue analysis-a review: 2001-2007," Forensic Science International, vol. 176, no. 2-3, pp. 93-110, 2008.

[11] B. David, C. Williams, and B. Carter, Transmission Electron Microscopy, Plenum Press, New York, NY, USA, 1996.

[12] R. Reed-Hill and R. Abbaschian, "Binary phase diagrams," in Physical Metallurgy Principles, PWS-Kent, Boston, Mass, USA, 3rd edition, 1992.

[13] R. Reed-Hill and R. Abbaschian, "Solidification of metals", in Physical Metallurgy Principles, PWS-Kent Publishing, Boston, Mass, USA, 3rd edition, 1992.

[14] R. Schmid, "A thermodynamic analysis of the $\mathrm{Cu}-\mathrm{O}$ system with an associated solution model," Metallurgical Transactions B, vol. 14, no. 3, pp. 473-481, 1983.

[15] K. A. Jackson, "On the theory of crystal growth: growth of small crystals using periodic boundary conditions," Journal of Crystal Growth, vol. 3-4, pp. 507-517, 1968.

[16] K. A. Jackson, "Mechanism of growth," in Proceedings of the Seminar on Liquid Metals and Solidification Held during the 39th National Metal Congress and Exposition, American Society for Metals, Chicago, Ill, USA, November 1957.

[17] Y. A. Chang and K.-C. Hsieh, Phase Diagrams of Ternary Copper-Oxygen-Metal Systems, ASM Press, Columbus, Ohio, USA, 1989.

[18] M. T. Clavaguera-Mora, J. L. Touron, J. Rodríguez-Viejo, and N. Clavaguera, "Thermodynamic description of the $\mathrm{Cu}-\mathrm{O}$ system," Journal of Alloys and Compounds, vol. 377, no. 1-2, pp. 8-16, 2004.

[19] D. A. Porter and K. E. Easterling, Phase Transformations in Metals and Alloys, Nelson Thornes Limited, Cheltenham, UK, 2nd edition, 2001.

[20] W. Kurz and D. J. Fisher, Fundamentals of Solidification, Trans Tech Publications, Dürnten, Switzerland, 3rd edition, 1989.

[21] M. C. Flemings, Solidification Processing, Mcgraw Hill Series in Materials Science and Engineering, McGraw-Hill, New York, NY, USA, 1974. 

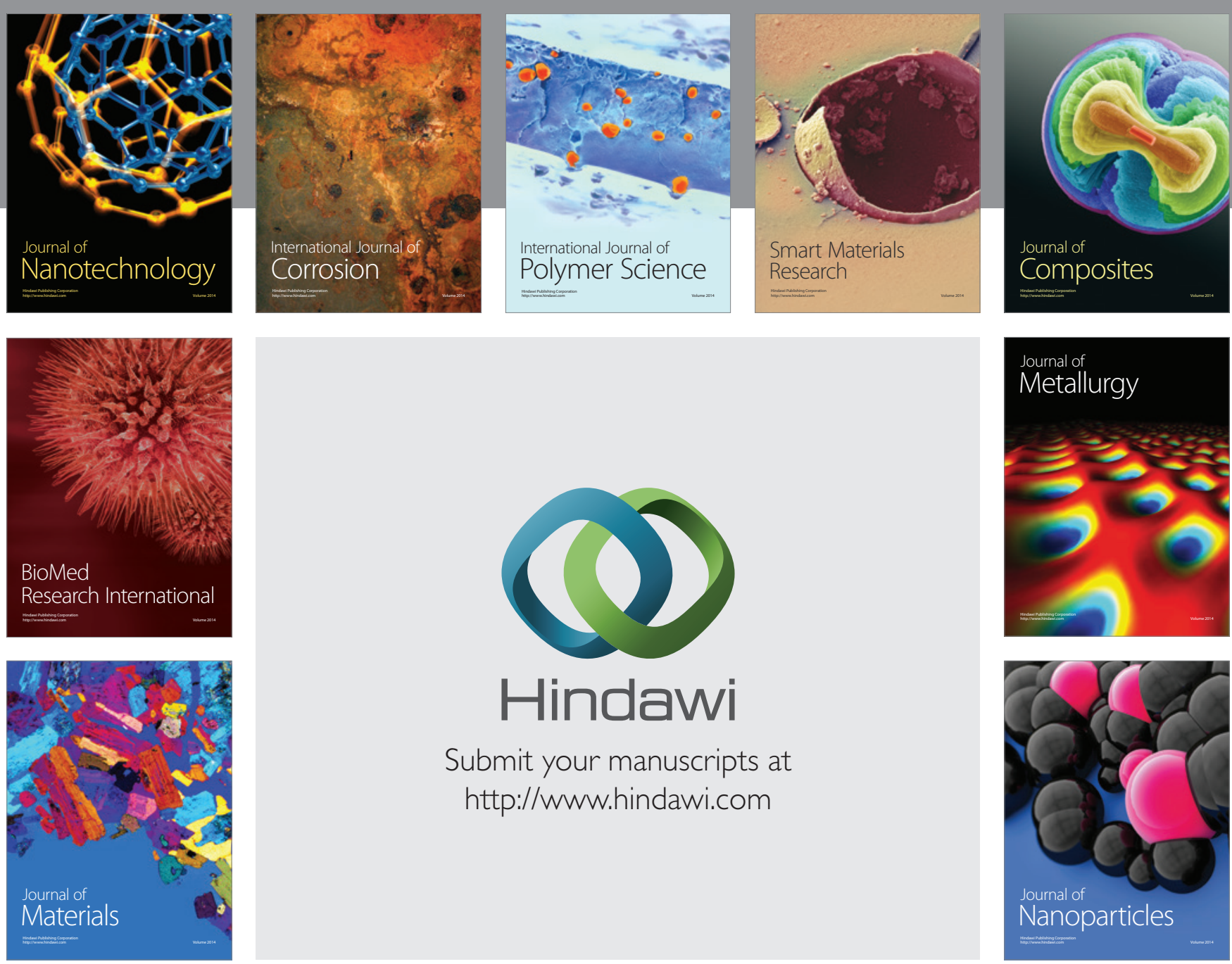

Submit your manuscripts at http://www.hindawi.com
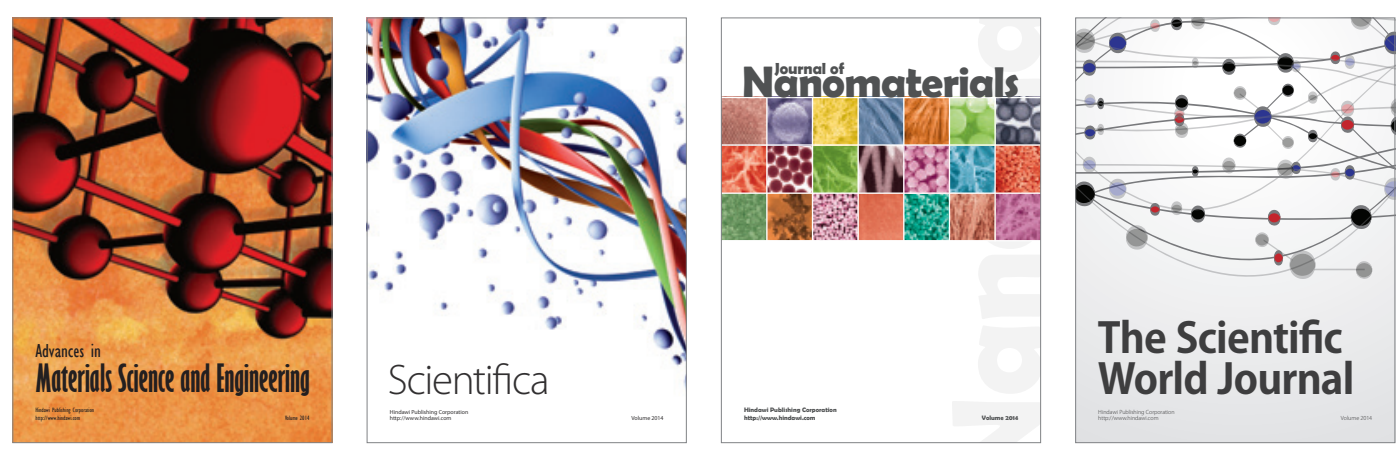

\section{The Scientific World Journal}
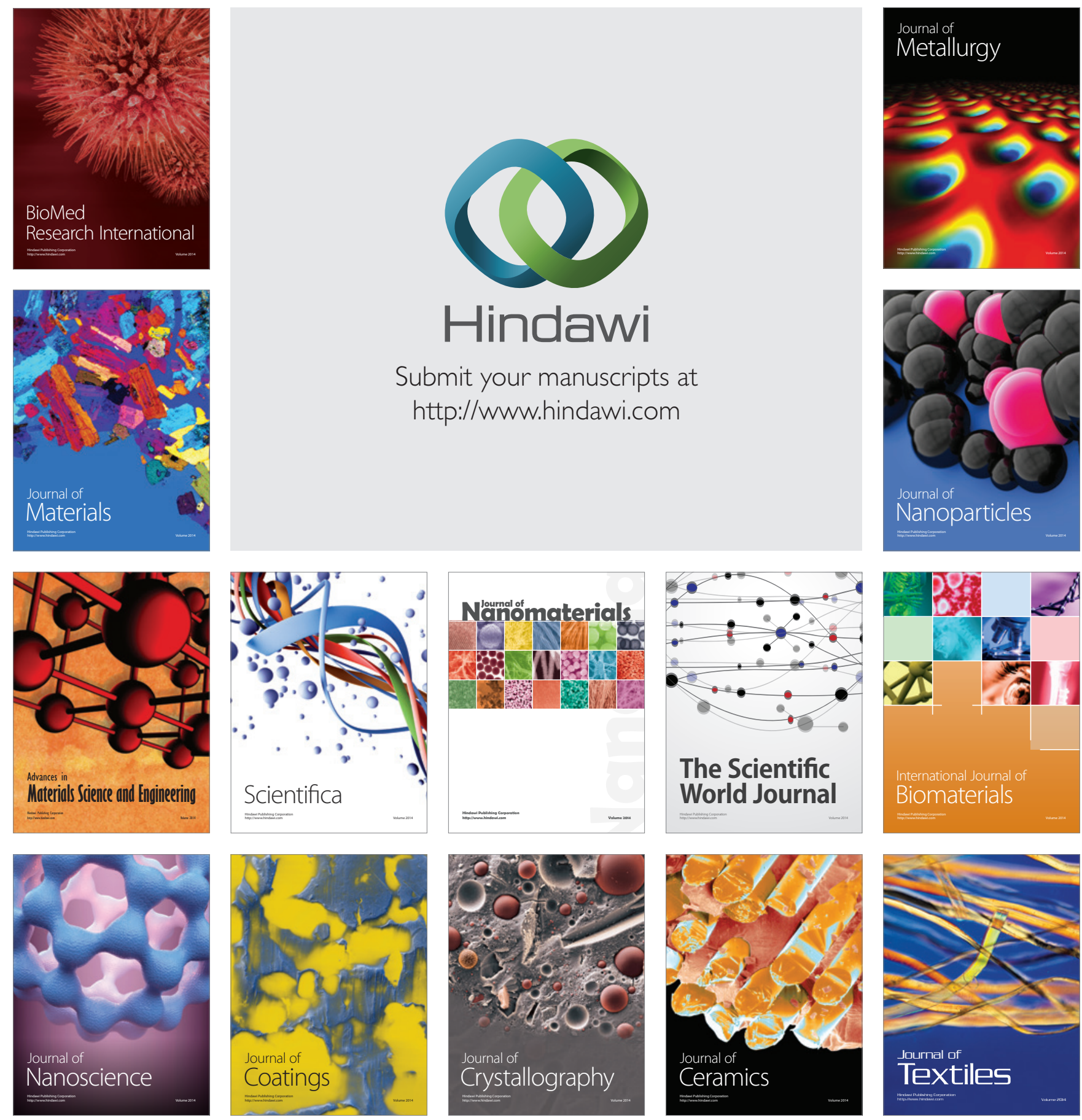